\title{
EXISTENCE AND MULTIPLICITY OF SOLUTIONS FOR SEMILINEAR ELLIPTIC SYSTEMS INVOLVING HARDY-SOBOLEV CRITICAL NONLINEARITY
}

\section{Nemat Nyamoradi And MoHsen SheKarbigi}

Abstract. This paper is concerned with a singular elliptic system, which involves the HardySobolev critical nonlinearity. The existence and multiplicity of solutions for this system are obtained by the variational methods. Mathematics subject classification (2010): 35A15, 35B33, 35J70.

Keywords and phrases: solution, critical Hardy-Sobolev exponent, elliptic system.

\section{REFERENCES}

[1] C. O. Alves, D. C. De Morais Filho, M. A. S. Souto, On systems of elliptic equations involving subcritical or critical Sobolev exponents, Nonlinear Anal., 42 (2000), 771-787.

[2] H. BRÈZIS, E. LIEB, A relation between pointwise convergence of functions and convergence of functionals, Proc. Amer. Math. Soc., 88 (1983), 486-490.

[3] H. Brèzis, L. Nirenberg, Positive solutions of nonlinear elliptic equations involving critical Sobolev exponents, Comm. Pure Appl. Math., 36 (1983), 437-477.

[4] L. Caffarelli, R. Kohn, L. NirenberG, First order interpolation inequality with weights, Compos. Math., 53 (1984), 259-275.

[5] D. CAO, P. HAN, Solutions for semilinear elliptic equations with critical exponents and Hardy potential, J. Differential Equat., 205 (2004), 521-537.

[6] F. Catrina, Z. WANG, On the Caffarelli-Kohn-Nirenberg inequalities: Sharp constants, existence (and nonexistence), and symmetry of external functions, Comm. Pure Appl. Math., 54, 2 (2001), 229_ 258.

[7] K. Chоu, C. Chu, On the best constant for a weighted Sobolev-Hardy inequality, J. London Math. Soc., 48, 1 (1993), 137-151.

[8] A. Ferrero, F. Gazzola, Existence of solutions for singular critical growth semi-linear elliptic equations, J. Differential Equat., 177, 2 (2001), 494-522.

[9] L. HuAnG, X. P. WU, C. L. TANG, Existence and multiplicity of solutions for semilinear elliptic equations with critical weighted Hardy-Sobolev exponents, Nonlinear Anal., 71 (2009), 1916-1924.

[10] X. J. HuAnG, X. P. Wu, C. L. TANG, Multiple positive solutions for semilinear elliptic equations with critical weighted Hardy-Sobolev exponents, Nonlinear Anal., 74 (2011), 2602-2611.

[11] D. KANG, S. J. PENG, Existence and asymptotic properties of solutions to elliptic systems involving multiple critical exponents, Science China Math., 54, (2) (2011), 243-256.

[12] D. KANG, On the elliptic problems with critical weighted Sobolev-Hardy exponents, Nonlinear Anal., 66, 5 (2007), 1037-1050.

[13] M. Lin, Some further results for a class of weighted nonlinear elliptic equations, J. Math. Anal. Appl., 337, 1 (2008), 537-546.

[14] P. H. Rabinowitz, Minimax Methods in Critical Point Theory with Applications to Differential Equations, in: CBMS Reg. Conf. Series. Math., vol. 65, Amer. Math. Soc, Providence, RI, 1986.

[15] B. XUAN, The solvability of quasilinear Brezis-Nirenberg-type problems with singular weights, Nonlinear Anal., 62 (2005), 703-725.

[16] L. WANG, Q. WEI, D. KANG, Existence and multiplicity of positive solutions to elliptic systems involving critical exponents, J. Math. Anal. Appl., 383 (2011), 541-552. 